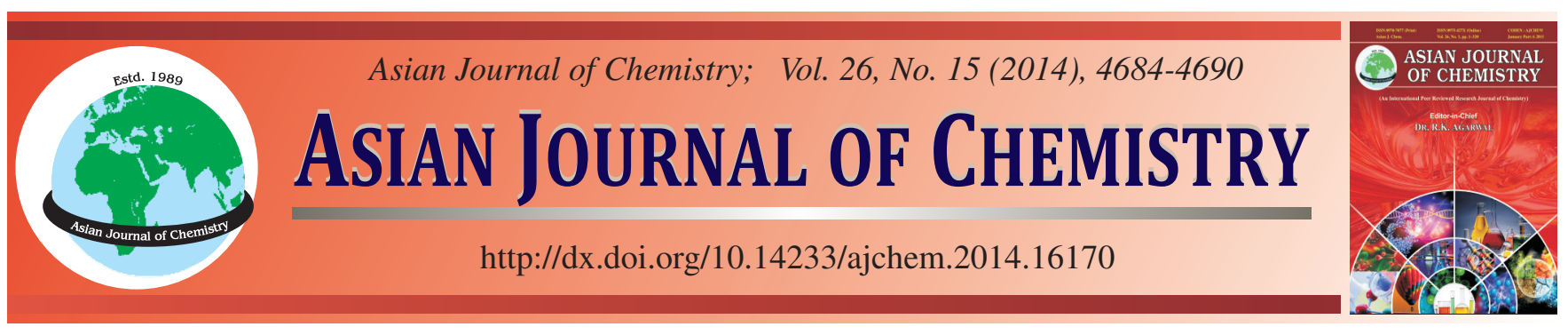

\title{
Optimization of Ultrasonic Assisted Extraction of Carbamate Pesticide Residues from Purple yam by Response Surface Method
}

\begin{abstract}
Z.F. WANG ${ }^{1}$, L. SHI ${ }^{1}$ and Y. MIN ${ }^{1, *}$
Department of Chemistry, Honghe University, Mengzi 661199, P.R. China

*Corresponding author: E-mail: minyong19741206@126.com

Received: 9 August 2013;

Accepted: 5 December 2013;

Published online: 16 July 2014;

AJC-15551

A novel and effective ultrasonic-assisted extraction technique is proposed for extracting carbamate pesticide residues from Purple yam. In the ultrasonic-assisted extraction technology, solvent types, solvent volume, ultrasound power, ultrasound extraction time and extraction times as significant factors were studied and optimized by response surface methodology over the extraction rate of the extracts, which the contents of extracts were determined by LC-MS. Response surface methodology analysis show good correspondence between experimental and predicted values. The adjusted coefficient of determination $\left(\mathrm{R}_{\mathrm{adj}}{ }^{2}\right)$ for the model was $94.33 \%$. Probability value $(\mathrm{P}<0.001)$ demonstrates a very high significance for the regression model. The extraction efficiency of five carbamate pesticides of $101.25 \%$ with ultrasonicassisted extraction was obtained by dual extraction with solvent volume of $30 \mathrm{~mL}$, ultrasonic power of $90 \mathrm{~W}$ and ultrasound extraction time of $15 \mathrm{~min}$. The proposed ultrasonic-assisted extraction technique has demonstrated to be simple, practical and environmentally friendly for the sample preparation.
\end{abstract}

Keywords: Purple yam, Carbamate pesticide residues, Ultrasonic-assisted extraction, Gel permeation chromatograph.

\section{INTRODUCTION}

Purple yam is a type of yam with purple to red coloured flesh, which belongs to the species of dioscorea alata $\mathrm{L}$ and is cultivated throughout the subtropical and tropical regions of the world for their edible corms, which constitute a staple food for many people in many tropical countries in West Africa, South Asia and South America ${ }^{1}$. Various functional components, such as mucin, dioscin, dioscorin, allantoin, choline, polyphenols, polyphenolases, vitamins and essential amino acids have been reported in yam tubers ${ }^{2-6}$. As for the Purple yam, the most interesting components are phenolic compounds, including anthocyanins ${ }^{7,8}$ and catechins ${ }^{6}$. Traditionally, yam can be used as Chinese herbal medicines to prevent the diarrhoea and diabetes. Recent research shows yam extracts can reduce blood sugar ${ }^{9}$ and blood lipid ${ }^{10}$, inhibit microbial activity $^{11}$ and possess antioxidant ${ }^{12}$, antimutagenic ${ }^{13}$ and antiallergic activities ${ }^{14}$.

Due to the Purple yam has potential health benefit for human beings, which is planted by large quantities. In order to control a wide range of insect pest species in agriculture, pesticides are widely used. Carbamates are one of the major classes of the pesticides that are widely used in agriculture due to their broad biological activity, low bioaccumulation potentials and relatively low mammalian toxicities ${ }^{15}$. However, carbamates affect the nervous system by disrupting an enzyme that regulates acetylcholine, a neurotransmitter. These compounds are considered hazardous to the environment and human health. Their acute toxicity is of great concern and therefore, the evaluation and monitoring of trace levels of carbamates are imperative.

For the analysis of carbamates pesticides in food, sample preparation is an important stage in the determination of carbamates pesticides in order to achieve a high extraction rate. Current methods for the extraction of pesticides in food typically involve several sample preparation steps such as extraction, clean-up and concentration before instrumental analysis. Few papers are reported on the extraction and cleanup of carbamate pesticide residues use liquid-liquid extraction ${ }^{16}$, supercritical fluid extraction ${ }^{17}$, microwave assisted extraction ${ }^{18}$, solid-phase microextraction ${ }^{19}$, etc. However, most of these techniques are time consuming and expensive, require large amounts of organic solvents and obtain a poor extraction efficiency. Therefore, developing a simple strategy for effectively extract carbamate pesticide from Purple yam remains scientifically challenging.

In this paper, we use a simple and facile ultrasonic-assisted extraction to extract the carbamate pesticide from Purple yam. After extraction, the obtained extracts were purified by gel permeation chromatograph directly in order to isolate the analytes from the complex matrices and remove interfering 
compounds. The significant variables (solvent types, solvent volume, ultrasound power, ultrasound extraction time and extraction times) was investigated and the experimental conditions was optimized by response surface methodology in order to obtain an optimal extraction effect.

\section{EXPERIMENTAL}

Pirimicarb (98.7\% purity), carbonfuran (98.6\% purity), aldicarb (98\% purity), methomyl (99.5\% purity), carbaryl ( $99.0 \%$ purity) were obtained from the ministry of agriculture environmental quality supervision and testing center. Purple yam was planted by pingbian of Yunnan province. Methanol and acetonitrile were HPLC grade and other reagents were of analytical grade. All aqueous solutions were prepared with doubly distilled water. GPC solution was a mixture of equal volume of ethyl acetate and cyclohexane.

A Shimadzu UFLC and triple quadrupole mass spectrometer system: LC-30 AD $\times 2$ infusion pump, DGU-20 A5 online degasser, SIL-30 AC autosampler, CTO-30 AC oven, CBM-20 A system controller, MS-8030 Lab Solution Ver. 5.41 chromatography workstation. Preplinc GPC \& accuvap (J2): AS4 autosampler, ASM system controller, HUB shared relay station, AccuPrep MPS gel purification chromatography system. Ultrasonic cleaner (SK 3300, purchased from Shanghai KUDO), Rotary evaporator (EYELA, purchased from Shanghai Ailang Instruments Co., Ltd.), Electronic balance (CP224C, purchased from Gustav Ohaus).

Analytical conditions: The HPLC system assembled from Shimadzu. A Shim-pack VP-ODS column $(150 \times 2 \mathrm{~mm}$ I.D) was used for separations and the column temperature was maintained at $40{ }^{\circ} \mathrm{C}$. The mobile phase was a mixture of methanol-water at a flow rate of $0.30 \mathrm{~mL} \mathrm{~min} \mathrm{~min}^{-1}$ (The initial concentration of methanol is $10 \%)$. The sample solution $(1 \mu \mathrm{L})$ was injected into the HPLC system. The time schedule is given in Table- 1 .

\begin{tabular}{cccc}
\multicolumn{5}{c}{ TABLE-1 } \\
\multicolumn{5}{c}{ EXPERIMENTAL CONDITIONS OF GRADIENT ELUTION } \\
\hline $\begin{array}{c}\text { Time } \\
(\mathrm{min})\end{array}$ & $\begin{array}{c}0.1 \%, \text { Formic } \\
\text { acid }(\%)\end{array}$ & $\begin{array}{c}\text { Methanol } \\
(\%)\end{array}$ & $\begin{array}{c}\text { Flow time } \\
\left(\mathrm{mL} \mathrm{mi}^{-1}\right)\end{array}$ \\
\hline 0.01 & 85 & 15 & 0.30 \\
2.00 & 74 & 26 & 0.30 \\
8.00 & 74 & 36 & 0.30 \\
9.00 & 60 & 40 & 0.30 \\
10.00 & 55 & 45 & 0.30 \\
15.00 & 20 & 80 & 0.30 \\
\hline
\end{tabular}

The LC-MS experiment was carried out on LCMS-8030. The LCMS-8030 heated ion source works with high-sensitivity detection using ESI. Ion source interface voltage is $4.5 \mathrm{kV}$. Select nitrogen as atomizing gas and and drying gas which gas flow rate is $3 \mathrm{~L} \mathrm{~min}^{-1}$ and $15 \mathrm{~L} \mathrm{~min}^{-1}$, respectively. Desolvation tube temperature is $250{ }^{\circ} \mathrm{C}$ and heating module temperature is $400{ }^{\circ} \mathrm{C}$. High speed multi-analyte detection with 500 multiple reaction monitoring (MRM) transitions in one second (dwell times of $1 \mathrm{msec}$ and pause times of $1 \mathrm{msec}$ ). The MRM detection parameters of five pesticide residues are shown in Table-2.

Sample extraction: The sample analyzed (Purple yam) was obtained from the pingbian market. Purple yam (200 g) was first peeled and chopped. Purple yam (1 g) was added into $1 \mathrm{~mL}$ mixed standard solutions and $30 \mathrm{~mL}$ GPC solution (15 mL ethyl acetate and $15 \mathrm{~mL}$ cyclohexane) ultrasonic extracted for $15 \mathrm{~min}$ and ultrasound power of $90 \mathrm{~W}$. After the pesticides were extracted one times, the resultant suspension was filtrated and the extracts were vacuum evaporated to recover the solvent. The concentrated solution was redissolved with $10 \mathrm{~mL}$ GPC solution and $5 \mathrm{~mL}$ was transferred to autosampler system supporting tube of GPC used for purification.

Sample purification: The sample was purified in gel permeation chromatograph (GPC). The gel purification column with $300 \mathrm{~mm} \times 25 \mathrm{~mm}$ (i.d.) was filled from top to bottom with $38 \mu \mathrm{m}-75 \mu \mathrm{m}$ height of Bio-Beads, S-X $\mathrm{X}_{3}$. Using ethyl acetate-cyclohexane (50: 50, v/v) mixture as mobile phase and pumping flow was $4.7 \mathrm{~mL} \mathrm{~min}^{-1}$. The detection wavelength was set at $210 \mathrm{~nm}$ and concentrated temperature was $45^{\circ} \mathrm{C}$. $5 \mathrm{~mL}$ extracted solution was transferred to autosampler system supporting tube of GPC for purifing. The eluent was collected according to peak time of mixed standard solution. The gel chromatography purification figure of five carbamate pesticides was shown in Fig. 1. It gives a sharp peak between 10 and 15 min show that the chromatographic peak of five car bamate pesticides and we collected effluent during this period. The obtained solution was concentrated and redissovled in $2 \mathrm{~mL}$ methanol and $1 \mu \mathrm{L}$ of the final solution was injected to the LC-MS column for analysis subsequently.

Experimental design: The extraction parameters were optimized using RSM, data analysis and model building with software Design Expert (Trial Version 8.0.6, Stat-Ease Inc., Minneapolis, Minnesota, USA). The Box-Behnken design with four variables was used to determine the response pattern and then to establish a model ${ }^{20}$. Box-Behnken design in the test

\begin{tabular}{|c|c|c|c|c|c|c|c|c|}
\hline \multicolumn{9}{|c|}{$\begin{array}{c}\text { TABLE-2 } \\
\text { MRM DETECTION PARAMETERS OF FIVE PESTICIDE RESIDUES IN LC-MS }\end{array}$} \\
\hline Number & Sample & Mode & Precursor ion & Quantitative ion & Qualitative ion & $\mathrm{Q}_{1}$ & $\mathrm{CE}$ & $\mathrm{Q}_{3}$ \\
\hline \multirow[b]{2}{*}{1} & \multirow{2}{*}{ Pirimicarb } & \multirow[b]{2}{*}{+} & \multirow{2}{*}{239.00} & \multirow{2}{*}{72.05} & \multirow{2}{*}{182.00} & -30.0 & -25.0 & -14.0 \\
\hline & & & & & & -25.0 & -25.0 & -18.0 \\
\hline \multirow{2}{*}{2} & \multirow{2}{*}{ Carbonfuran } & \multirow{2}{*}{+} & \multirow{2}{*}{222.00} & \multirow{2}{*}{165.05} & \multirow{2}{*}{123.05} & -10.0 & -10.0 & -18.0 \\
\hline & & & & & & -23.0 & -20.0 & -24.0 \\
\hline \multirow{2}{*}{3} & \multirow{2}{*}{ Aldicarb } & \multirow{2}{*}{+} & \multirow{2}{*}{213.00} & \multirow{2}{*}{89.05} & \multirow{2}{*}{116.0} & -14.0 & -15.0 & -17.0 \\
\hline & & & & & & -22.0 & -10.0 & -23.0 \\
\hline \multirow{2}{*}{4} & \multirow{2}{*}{ Methomyl } & \multirow{2}{*}{+} & \multirow{2}{*}{163.00} & \multirow{2}{*}{88.00} & \multirow{2}{*}{145.05} & -16.0 & -10.0 & -16.0 \\
\hline & & & & & & -16.0 & -10.0 & -21.0 \\
\hline \multirow[t]{2}{*}{5} & \multirow{2}{*}{ Carbaryl } & \multirow{2}{*}{+} & \multirow{2}{*}{202.00} & \multirow{2}{*}{127.00} & \multirow{2}{*}{106.05} & -13.0 & -10.0 & -30.0 \\
\hline & & & & & & -13.0 & -30.0 & -15.0 \\
\hline
\end{tabular}




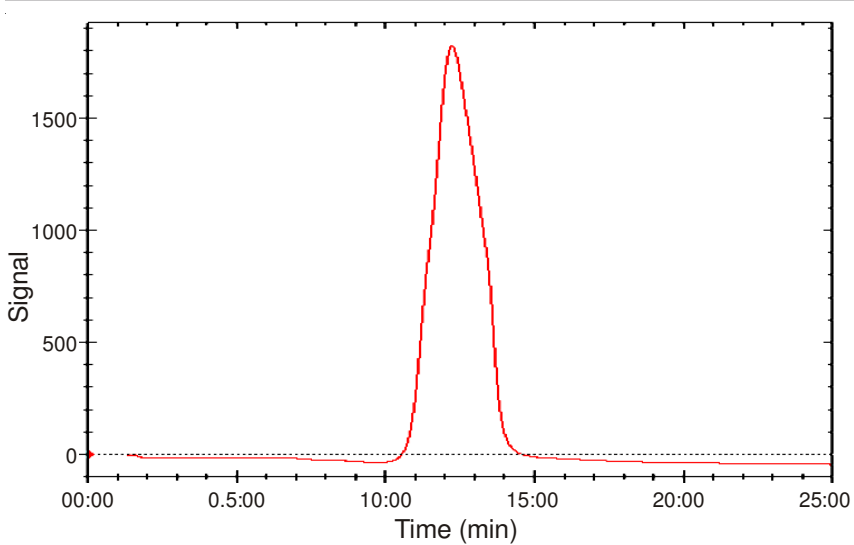

Fig. 1. Gel permeation chromatography purification of five carbamate pesticides

design consists of twenty four factorial points and five replicates of the central point. Twenty-four experiments were augmented with five replications at the center points to evaluate the pure error ${ }^{21}$. The parameters and their levels were ultrasound power $(80-100 \mathrm{~W})$, extraction time (10-20 min), solvent volume $(25-35 \mathrm{~mL})$ and extraction times (1-3 times). The symbols and levels are shown in Table-3. The ultrasonic conditions were optimized to obtain the maximal extraction efficiency of pesticide residues by this software. Experimental runs were randomised to minimize the effects of unexpected variability in the observed responses. The behaviour of the system was explained by the following second-order polynomial equation ${ }^{22}$ :

$$
\begin{gathered}
Y \%=A_{0}+A_{1} X_{1}+A_{2} X_{2}+A_{3} X_{3}+A_{4} X_{4}+A_{5} X_{1} X_{2} \\
+A_{6} X_{1} X_{3}-A_{7} X_{1} X_{4}-A_{8} X_{2} X_{3}-A_{9} X_{2} X_{4}+A_{10} X_{3} X_{4} \\
-A_{11} X_{12}-A_{12} X_{22}-A_{13} X_{32}-A_{14} X_{42}
\end{gathered}
$$

where $\mathrm{Y}$ is the extraction efficiency of pesticide residues; $\mathrm{A}_{0}$ is constant; $A_{1}, A_{2}, A_{3}$ and $A_{4}$ are linear coefficients; $A_{5}, A_{6}, A_{7}$, $\mathrm{A}_{8}, \mathrm{~A}_{9}$ and $\mathrm{A}_{10}$ are cross-product coefficients; $\mathrm{A}_{11}, \mathrm{~A}_{12}, \mathrm{~A}_{13}$ and $\mathrm{A}_{14}$ are quadratic coefficients.

\begin{tabular}{lccc}
\multicolumn{4}{c}{ TABLE-3 } \\
\multicolumn{3}{c}{ INDEPENDENT VARIABLES AND THEIR } \\
LEVELS FOR BOX-BEHNKEN DESIGN \\
\hline \multirow{2}{*}{ Independent variables } & \multicolumn{3}{c}{ Levels } \\
\cline { 2 - 4 } & -1 & 0 & +1 \\
\hline Ultrasound power (W) & 80 & 90 & 100 \\
Extraction time (min) & 10 & 15 & 20 \\
Solvent volume (mL) & 25 & 30 & 35 \\
Extraction times (times) & 1 & 2 & 3 \\
\hline
\end{tabular}

\section{RESULTS AND DISCUSSION}

The ultrasonic-assisted extraction technology was used to extract the carbamate pesticide from Purple yam. This strategy is known to obtain a high extraction efficiency due to the ultrasonic-assisted extraction technology has several important benefits. First, the procedure is very simple and can be performed at room temperature which prevents carbamates from decomposing due to the thermal instability of carbamates. Second, ultrasound can effectively improve the extraction rate by increasing the mass transfer rates and possible rupture of cell wall due to formation of microcavities leading to higher product yields with reduced processing time and solvent consumption. The significant variables (ultrasonic extraction solvents, ultrasonic power, ultrasonic time, extraction agent's amounts and extraction times) was investigated and response surface methodology was used to optimize experimental conditions in order to obtain a maximum extraction efficiency. The obtained extracts were purified by gel permeation chromatograph directly in order to isolate the analytes from the complex matrices and remove interfering compounds after extraction. In this work, the GPC solution (mix cyclohexane and ethyl acetate with equal volume) not only use as extraction solvent of extracting carbamate pesticide from Purple yam, but also the mobile phase of gel permeation chromatograph. That will avoid the errors which produced by conversion errors. Furthermore, the gel permeation chromatograph can achieve online monitoring which will be benefit for collecting sample.

Selection of extraction solvent: The selection of an appropriate extraction solvent is critical to the ultrasonic assisted extraction technology since its physicochemical properties affect the extraction effect. The extraction solvent should meet high extraction capability for the target analytes. Based on the considerations, GPC solution, acetonitrile, dichloromethane, acetone and toluene were selected as potential extraction solvents for the study. Fig. 2 shows the effect of the extraction solvents (GPC solution, acetonitrile, dichloromethane, acetone and toluene) on the extraction rate. In case of GPC solution as extraction solvent, the extraction rates are high for most of the analytes in addition to methomyl. This could be because GPC solution is a binary extraction solvent system of ethyl acetate and cyclohexane. The binary solvent system can take advantages of the different extraction abilities of both ethyl acetate and cyclohexane for different analytes. The mixture of the two extraction solvents might alter their individual properties and the result showed a synergic effect of the binary extraction solvent system on the extraction of the analytes. The result shows that the GPC solution is the optimum solvent from the total extraction rate.

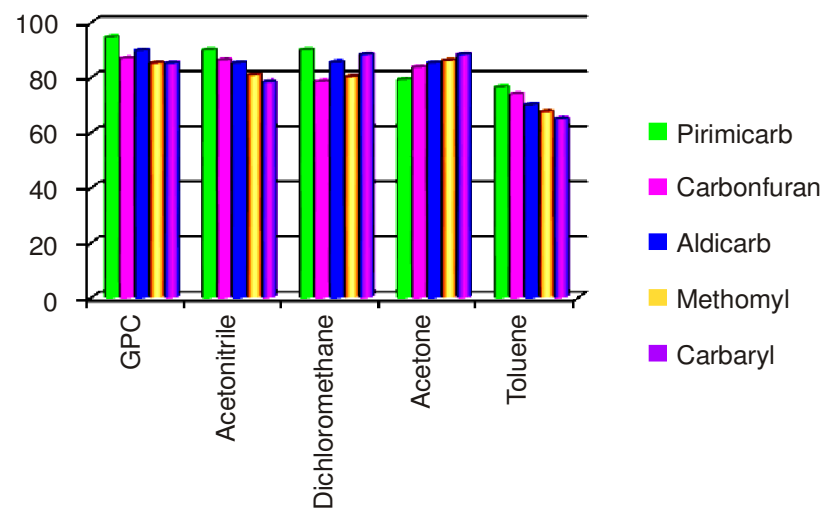

Fig. 2. Effects of different extraction solvents on the extraction rate of the carbamate pesticide

Effect of extraction solvent volume: In order to study the effect of the volume of the extraction solvent on the performance of the presented ultrasonic assisted extraction method. In this experiment, the amount of added Purple yam was maintained $1 \mathrm{~g}$, the volume of ethyl acetate-cyclohexane (1:1, 
$\mathrm{v} / \mathrm{v}$ ) was varied in the range from 20 to $40 \mathrm{~mL}$, ultrasound extraction 15 min with $90 \mathrm{~W}$ and extraction one times. The results were shown in Fig. 3. When the extraction solvent volume was increased, the extraction rates were increased until $40 \mathrm{~mL}$. At higher volumes than $30 \mathrm{~mL}$, the extraction rates almost remained constant. From the obtained results, $30 \mathrm{~mL}$ of GPC solution was chosen for further studies.

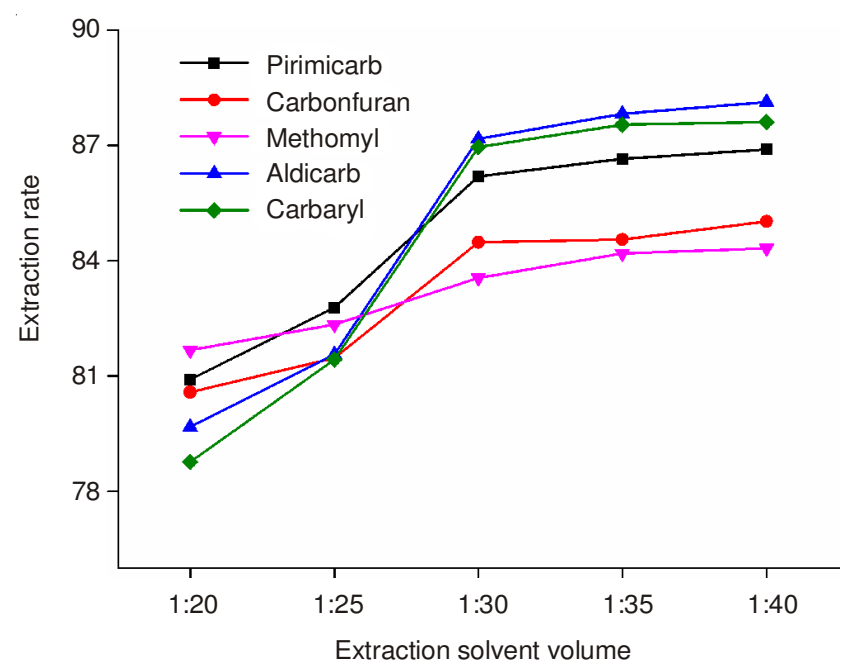

Fig. 3. Effects of extraction solvent volume on the extraction rate of the carbamate pesticide

Effect of ultrasound power: Ultrasound power is another important parameter for effective extraction. The effect of the ultrasound power was studied over the power range between $60 \mathrm{~W}$ and $100 \mathrm{~W}$. The results (Fig. 4) indicated that the extraction rates are increased by increasing the ultrasound power before $100 \mathrm{~W}$, but extraction rate has no visible change between $90 \mathrm{~W}$ and $100 \mathrm{~W}$ which means that field density is already high for the extraction of carbamate pesticide. Therefore, $90 \mathrm{~W}$ of ultrasound power was chosen for the experiments.

Effect of ultrasound extraction time: Ultrasound extraction time is one of the main factors in ultrasonic assisted extraction method as in most extraction procedures. It affects

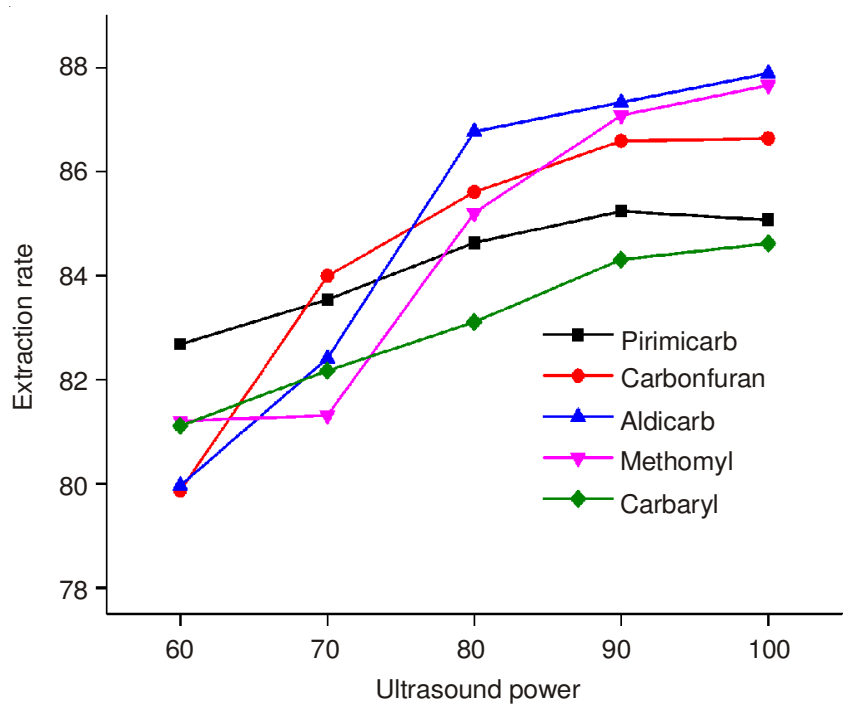

Fig. 4. Effect of ultrasouod power on the extraction rate of the carbamate pesticide mass transfer process and thus influences the extraction rate of the analytes. The ultrasound extraction time was defined as the time interval between the addition of the extraction solvent (GPC solution) to the sample (the start of the sonication) and the end of the sonication. The effect of the ultrasound extraction time was studied over the time range between 5 and $25 \mathrm{~min}$. The results (Fig. 5) indicated that the extraction rates are increased by increasing the extraction time before $15 \mathrm{~min}$ and after that, remained almost constant. Therefore, $15 \mathrm{~min}$ of sonication time was chosen for the experiments.

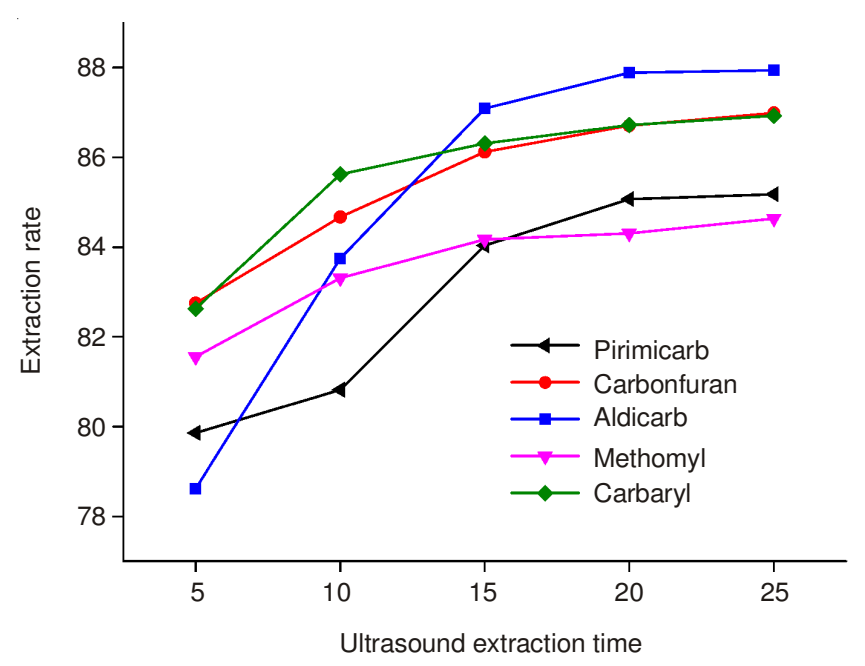

Fig. 5. Effect of ultrasound extraction time on the extraction rate of the carbamate pesticide

Effect of the ultrasound extraction times: The effect of extraction times was investigated in this experiment (Fig. 6). A compound of $1 \mathrm{~g}$ purple and $1 \mathrm{~mL}$ mixed standard solutions was extracted with $30 \mathrm{~mL}$ GPC solution under ultrasound power of $90 \mathrm{~W}$ and ultrasound extraction $15 \mathrm{~min}$. The residue was taken back and re-extracted four times under the abovementioned conditions. The extraction efficiency of five carbamate pesticides extracted by 2, 3 and 4 times were respectively $99.25,101.71$ and $101.98 \%$. The extraction efficiency of two times accounted for $97.6 \%$ of the extraction efficiency of the third times and the third extraction accounted for only $2.5 \%$ of the extraction efficiency of the third times. So extraction two times was chosen for the experiments.

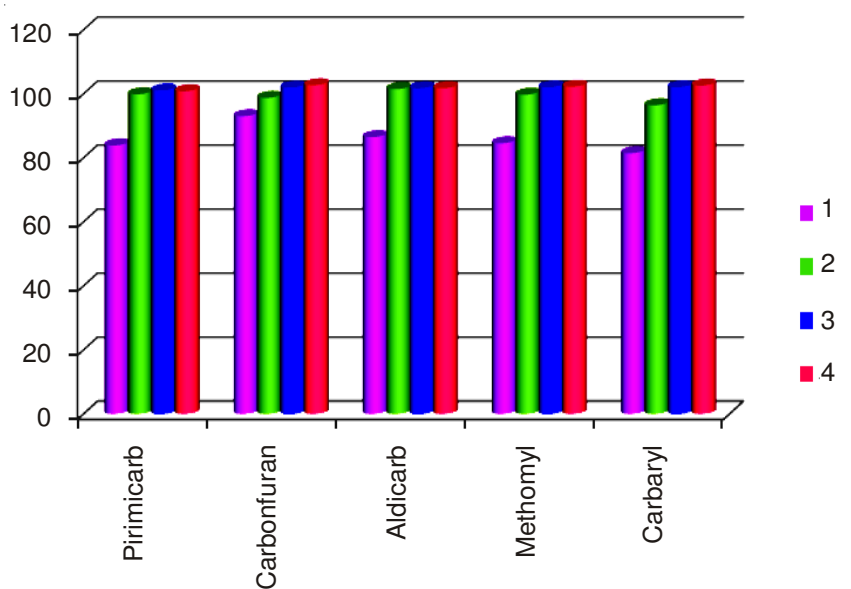

Fig. 6. Effect of ultrasound extraction times on the extraction rate of the carbamate pesticide 
Response surface methodology model fitting: It was necessary to investigate the extraction variables in order to determine the best combination of variables for the extraction efficiency of pesticide residue from Purple yam. The total number of experiments $(\mathrm{N})$ in a Box-Behnken design can be calculated using the following eqn. (1):

$$
\mathrm{N}=2^{\mathrm{k}}+2 \mathrm{k}+\mathrm{x}_{0}
$$

where $\mathrm{k}$ is the number of variables and $\mathrm{x}_{0}$ is the number of central points. Thus a three-level-four-factor Box-Behnken design was employed in this study, requiring $29\left(\mathrm{k}=4 ; \mathrm{x}_{0}=5\right)$ experiments for the optimization of extraction parameters. Twenty nine experiments were performed according to Table-3 to optimize the parameters ${ }^{23}$. Twenty-four experiments were augmented with five replications at the center points to evaluate the pure error ${ }^{21}$. The experimental data in terms of extraction efficiency are shown in Table-4.

\begin{tabular}{|c|c|c|c|c|c|}
\hline & \multicolumn{5}{|c|}{$\begin{array}{c}\text { TABLE } 4 \\
\text { BOX-BEHNKEN DESIGN AND THE EXTRACTION } \\
\text { EFFICIENCY }\end{array}$} \\
\hline & $\begin{array}{c}\mathrm{X}_{1} \\
\text { Ultrasound } \\
\text { power }(\mathrm{W})\end{array}$ & $\begin{array}{c}\mathrm{X}_{2} \\
\text { Extraction } \\
\text { time (min) }\end{array}$ & $\begin{array}{c}\mathrm{X}_{3} \\
\text { Solvent } \\
\text { volume } \\
(\mathrm{mL})\end{array}$ & $\begin{array}{c}\mathrm{X}_{4} \\
\text { Extraction } \\
\text { times } \\
\text { (times) }\end{array}$ & $\begin{array}{l}\text { Extraction } \\
\text { efficiency } \\
\quad(Y \%)\end{array}$ \\
\hline 1 & 0 & -1 & 0 & 1 & 101.31 \\
\hline 2 & 0 & 0 & 1 & -1 & 83.08 \\
\hline 3 & -1 & 0 & 1 & 0 & 94.83 \\
\hline 4 & 1 & 0 & 1 & 0 & 100.32 \\
\hline 5 & 1 & 0 & 1 & 0 & 95.11 \\
\hline 6 & 1 & 0 & -1 & 1 & 98.08 \\
\hline 7 & 0 & -1 & 0 & 0 & 98.31 \\
\hline 8 & 0 & 0 & -1 & 0 & 100.02 \\
\hline 9 & 1 & 1 & 0 & 0 & 102.16 \\
\hline 10 & 0 & 0 & 0 & 0 & 102.04 \\
\hline 11 & 0 & 0 & 0 & -1 & 85.76 \\
\hline 12 & 0 & 0 & -1 & 0 & 101.91 \\
\hline 13 & -1 & 1 & 0 & 0 & 94.18 \\
\hline 14 & 0 & 1 & 0 & 0 & 94.12 \\
\hline 15 & 0 & 0 & -1 & 1 & 102.77 \\
\hline 16 & -1 & 0 & -1 & 0 & 94.36 \\
\hline 17 & -1 & 0 & -1 & 1 & 96.81 \\
\hline 18 & -1 & -1 & 0 & 0 & 96.18 \\
\hline 19 & 0 & 1 & 0 & -1 & 89.86 \\
\hline 20 & -1 & 0 & 0 & -1 & 81.23 \\
\hline 21 & -1 & -1 & 0 & 0 & 96.11 \\
\hline 22 & 0 & 1 & 1 & 0 & 102.95 \\
\hline 23 & 0 & 0 & 0 & 0 & 101.19 \\
\hline 24 & 0 & 1 & 0 & 1 & 101.41 \\
\hline 25 & 0 & 0 & 0 & 0 & 101.33 \\
\hline 26 & 0 & -1 & 0 & -1 & 83.52 \\
\hline 27 & 0 & -1 & 1 & 0 & 100.78 \\
\hline 28 & 1 & 0 & 0 & -1 & 84.67 \\
\hline 29 & 0 & 0 & -1 & 1 & 100.15 \\
\hline
\end{tabular}

The effects of each factor and their interaction were calculated using a Design Expert program (version 8.0.6). Fitting the data with various models and, subsequently, the analysis of variance (ANOVA) showed that extraction efficiency was best described with quadratic polynomial model. The ANOVA pesticide residue extraction efficiency was shown in Table-5. The correlation measure for testing the goodness of fit of the regression equation is the adjusted determination coefficient $\left(\mathrm{R}^{2}{ }_{\text {Adj }}\right)$. The value of $\mathrm{R}^{2}$ Adj is determined to be 0.9433 and reasonably close to 1 , which indicates that the regression models defined well the true behaviour of the system.

The quadratic polynomial model was highly significant and sufficient to represent the actual relationship between the response and significant parameters with very low p-value $(<0.0001)$ from the ANOVA (Table-5). Here, the p-value of the model was smaller than 0.001 , which indicated that the model was suitable for use in this experiment. The $\mathrm{p}$-value of "lack of fit" was 0.0672 (P > 0.01), which indicated that "lack of fit" was insignificant relative to the pure error. The values indicated that, the accuracy and general availability of the polynomial model were adequate ${ }^{24}$. The model F-value (34.26) implies it was significant at $95 \%$ confidence level. The model also showed statistically insignificant lack of fit, as is evident from the computed F-values of 5.01 at $95 \%$ confidence level. Furthermore the value of pure error was low, which indicates good reproducibility of the data obtained with a small p-value from the ANOVA and a satisfactory coefficient of determination (Table-5). The coefficient of determination also revealed that there are excellent correlations between the independent variables. Furthermore, from the p-values of each model term, it could be concluded that the regression coefficients of the linear term $\mathrm{X}_{1}, \mathrm{X}_{2}, \mathrm{X}_{3}, \mathrm{X}_{4}$ and all the quadratic terms had some effect on extraction efficiency. Among them, $X_{1}, X_{3}, X_{4}, X_{1} X_{2}$, $X_{12}$ and $X_{42}$ had significant effect on extraction efficiency. They were all significant at $1 \%$ level. Therefore the effect of each model term on the extraction yield is not linear relationship.

\begin{tabular}{|c|c|c|c|c|c|}
\hline \multicolumn{6}{|c|}{$\begin{array}{l}\text { TABLE-5 } \\
\text { ANALYSIS OF VARIANCE (ANOVA) OF THE } \\
\text { QUADRATIC POLYNOMIAL MODEL }\end{array}$} \\
\hline Source & $\begin{array}{l}\text { Sum of } \\
\text { squares }\end{array}$ & d.f. & $\begin{array}{l}\text { Mean } \\
\text { square }\end{array}$ & F-value & $\begin{array}{l}\text { Probability } \\
\text { (P) }\end{array}$ \\
\hline $\mathrm{X}_{1}$ & 30.08 & 1 & 30.08 & 12.12 & $0.0037 * *$ \\
\hline $\mathrm{X}_{2}$ & 5.98 & 1 & 5.98 & 2.41 & 0.1429 \\
\hline $\mathrm{X}_{3}$ & 23.86 & 1 & 23.86 & 9.61 & $0.0078 * *$ \\
\hline $\mathrm{X}_{4}$ & 711.63 & 1 & 711.63 & 286.76 & $<0.0001$ \\
\hline $\mathrm{X}_{1} \mathrm{X}_{2}$ & 15.64 & 1 & 15.64 & 6.30 & $0.0249 *$ \\
\hline $\mathrm{X}_{1} \mathrm{X}_{3}$ & 5.62 & 1 & 5.63 & 2.26 & 0.1547 \\
\hline $\mathrm{X}_{1} \mathrm{X}_{4}$ & 1.18 & 1 & 1.18 & 0.47 & 0.5022 \\
\hline $\mathrm{X}_{2} \mathrm{X}_{3}$ & 10.11 & 1 & 10.11 & 4.07 & 0.0631 \\
\hline $\mathrm{X}_{2} \mathrm{X}_{4}$ & 9.73 & 1 & 9.73 & 3.92 & 0.0676 \\
\hline $\mathrm{X}_{3} \mathrm{X}_{4}$ & 7.02 & 1 & 7.02 & 2.83 & 0.1147 \\
\hline $\mathrm{X}_{1}^{2}$ & 94.32 & 1 & 94.32 & 38.01 & $<0.0001 * *$ \\
\hline $\mathrm{X}_{2}^{2}$ & 1.35 & 1 & 1.35 & 0.55 & 0.4723 \\
\hline $\mathrm{X}_{3}^{2}$ & 14.36 & 1 & 14.61 & 5.89 & 0.0294* \\
\hline $\mathrm{X}_{4}^{2}$ & 316.65 & 1 & 316.65 & 127.60 & $<0.0001 * *$ \\
\hline Residual & 34.74 & 14 & 2.48 & & \\
\hline Lack of fit & 32.17 & 10 & 3.22 & 5.01 & 0.0672 \\
\hline Pure error & 2.57 & 4 & 0.64 & & \\
\hline Cor total & 1225.00 & 28 & & & \\
\hline Model & 1190.26 & 14 & 85.02 & 34.26 & $<0.0001$ \\
\hline $\begin{array}{l}\mathrm{R}^{2}= \\
0.9716\end{array}$ & $\begin{array}{l}\mathrm{R}_{\text {adi }}^{2}= \\
0.9433\end{array}$ & & & & \\
\hline
\end{tabular}

Using the designed experimental data (Table-4), the polynomial model for the extraction efficiency of pesticide residue was regressed and shown as below (in term of coded factors): 
$\mathrm{Y} \%=101.30+1.58 \mathrm{X}_{1}+0.71 \mathrm{X}_{2}+1.41 \mathrm{X}_{3}+7.70 \mathrm{X}_{4}$

$+1.98 \mathrm{X}_{1} \mathrm{X}_{2}+1.18 \mathrm{X}_{1} \mathrm{X}_{3}-0.54 \mathrm{X}_{1} \mathrm{X}_{4}-1.59 \mathrm{X}_{2} \mathrm{X}_{3}-1.56 \mathrm{X}_{2} \mathrm{X}_{4}$

$+1.32 X_{3} X_{4}-3.81 X_{1}^{2}-0.46 X_{2}^{2}-1.50 X_{3}^{2}-6.99 X_{4}^{2}$

Many parameters can influence the performance of extraction efficiency from pesticide residue. Eqn. 2 showed that extraction efficiency had a complex relationship with independent variables that encompass both first and second-order polynomials. The best way of expressing the effect of any parameter on the extraction efficiency within the experimental space under investigated was to generate response surface plots of the equation.

Response surface analysis of extraction efficiency: To investigate the interactive effects of operational parameters on extraction efficiency, the three dimensional profiles of multiple non-linear regression model were depicted in Fig. 7 ,
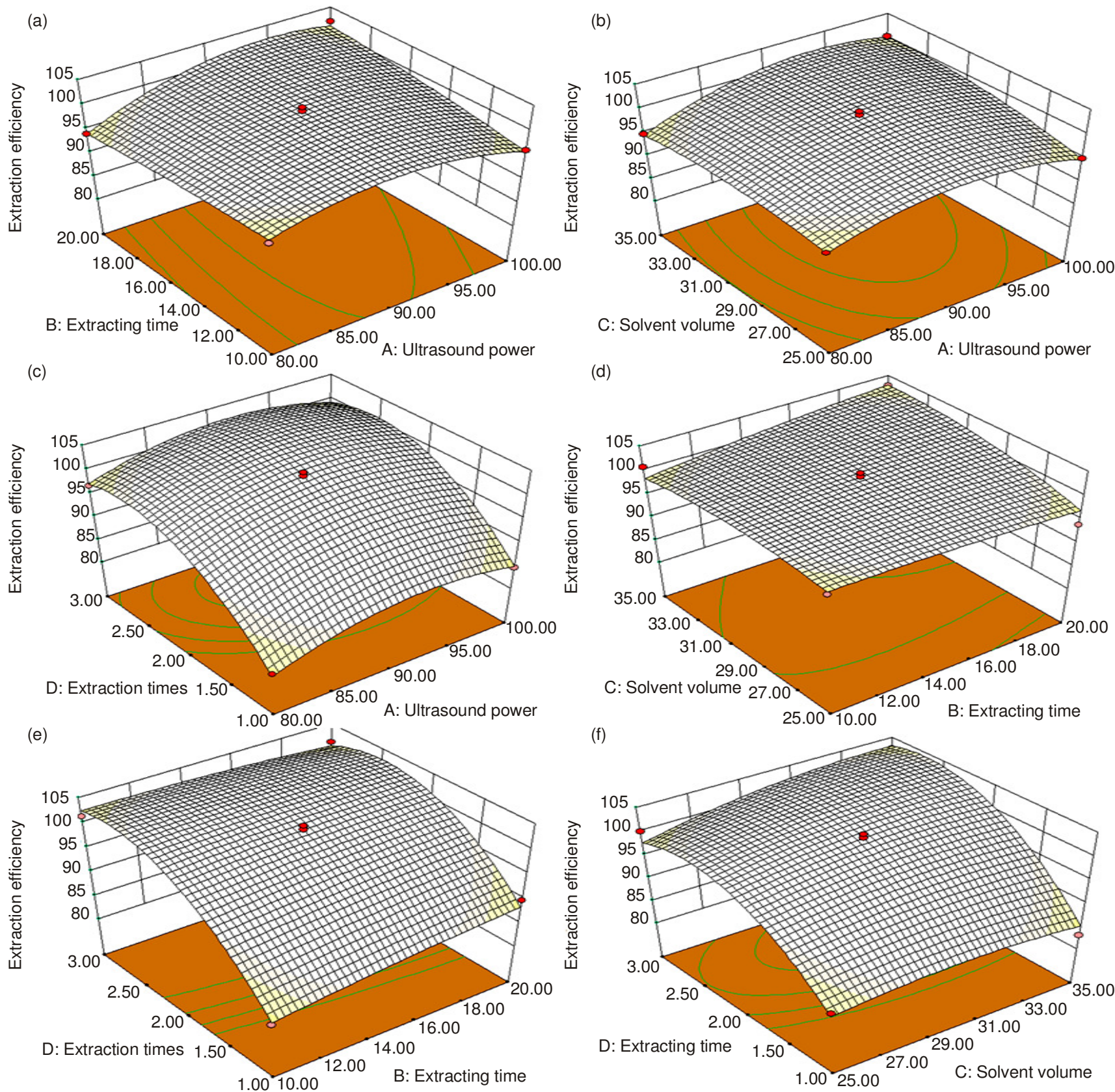

when the other parameter was kept constant. The relationship between extraction parameters and total phenolic content were investigated by response surface plots. Fig. 7 shows the effect of extraction time, ultrasound power, solvent volume, extraction times and their mutual interaction on the extraction efficiency. The highest extraction efficiency was observed at extraction time of $15 \mathrm{~min}$ and ultrasound power $90 \mathrm{~W}$ (Fig. 7a). However, the increase in ultrasound power at a fixed extraction time led to an increase in the extraction efficiency, but reached a maximum at the ultrasound power of $90 \mathrm{~W}$ (Fig. 7a). High ultrasound power can increase diffusion, mechanical forces and thermal impact, which result in disruption of cells walls, reduce particle size and enhance mass transfer across cell membranes ${ }^{25}$. However, the ultrasound power of $100 \mathrm{~W}$ extraction appeared to be disadvantaged on the extract. It implied that although
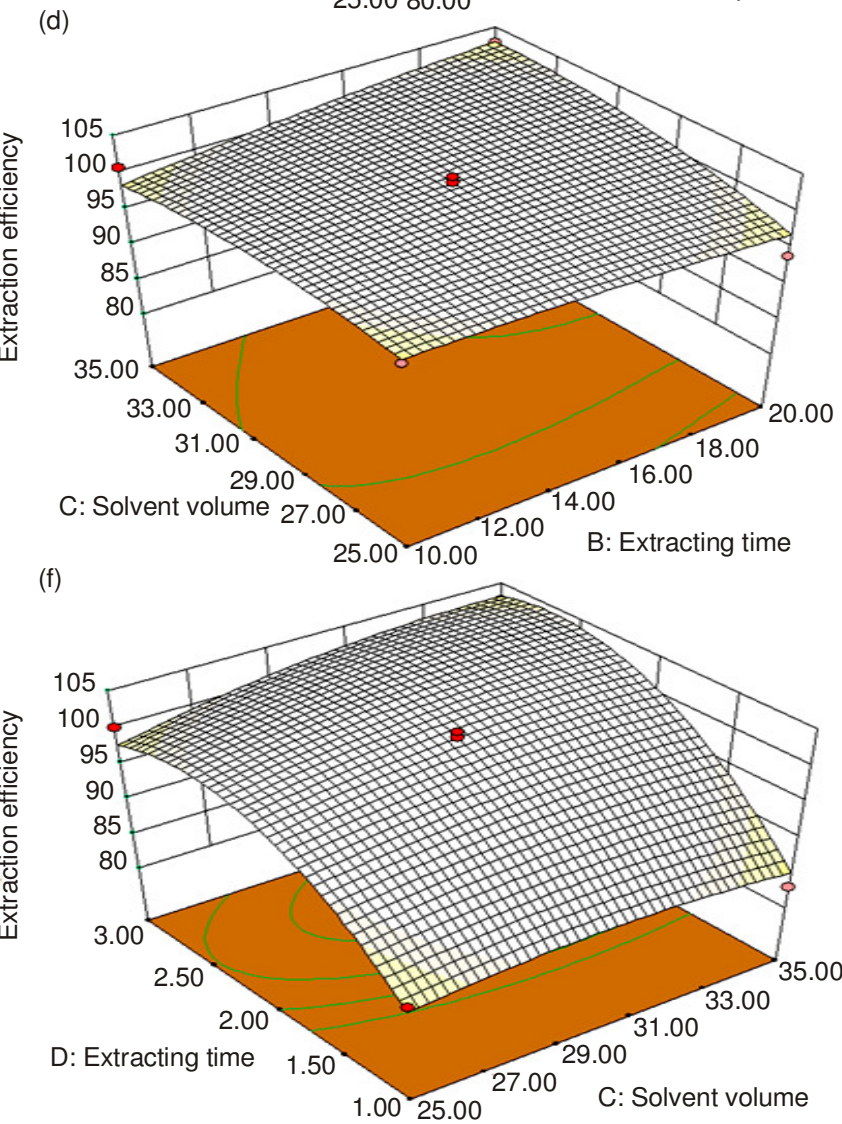

Fig. 7. Response surface plots of purple yam showing the effect of (a) extraction time and ultrasound power, (b) solvent volume and ultrasound power, (c) extraction times and ultrasound power, (d) solvent volume and extraction time, (e) extraction times and extraction time, (f) extraction times and solvent volume on extraction efficiency 
increase in ultrasound power could accelerate diffusion of molecule, which could be favorable to increase in extraction efficiency, the advantage could be offset by decomposition of Purple yam with prolong of the ultrasound time and ultrasound power arrived at the optimal values ${ }^{26}$.

The effect of ultrasound power and solvent volume shown in Fig. $7 \mathrm{~b}$ demonstrated that the extraction efficiency achieved a maximum at the ultrasound power of $90 \mathrm{~W}$ and solvent volume of $30 \mathrm{~mL}$ (Fig. 7 b). Fig. 7c shows the effect of extraction times and ultrasound power on the ultrasonic-assisted extraction of carbamate pesticide residues from Purple yam. Extraction efficiency of extraction two times is dramatically increased compared with extraction one times. When continue to increase the extraction times, extraction efficiency was worse instead. The effect of extraction time and solvent volume shown in Fig. 7d, increase of solvent volume from 25 to $30 \mathrm{~mL}$ with increase of from about 10 to 15 min enhance extraction efficiency, while more than $15 \mathrm{~min}$ extraction appeared to be disadvantage on the extract. It could be explained that, as the extraction time and solvent volume prolonged, the chemical decomposition of Purple yam compound present in extract may occur, resulting in a decrease in extraction efficiency. Fig. 7 e,f show the effect of extraction times and extraction time, extraction times and solvent volume on the extraction efficiency, respectively. The extraction efficiency achieved a maximum at the extraction twice and extraction time of $15 \mathrm{~min}$ (Fig. 7e) and extraction twice and solvent volume of $30 \mathrm{~mL}$ (Fig. 7f).

Validation of the model: According to RSM result, the optimum ultrasonic-assisted extraction conditions for the extraction efficiency of carbamate pesticide residues from Purple yam as follows: solvent volume of $30 \mathrm{~mL}$, ultrasonic power of $90 \mathrm{~W}$, ultrasound extraction time of $15 \mathrm{~min}$ and ultrasound extraction twice. The experiment was carried out at the optimized conditions.

Carbamate pesticide residues extraction efficiency of $101.25 \%$ was obtained and was in good agreement with the predicted one (103.374\%). The accuracy of the model was validated with quadruplicate experiments under the aforementioned optimal reaction conditions (Table-6). As a result, the model from Box-Behnken experimental design was considered to be accurate and reliable for predicting the extraction efficiency extracts obtained from Purple yam for ultrasonic assisted extraction.

TABLE-6

EXTRACTION EFFICIENCY OF FIVE CARBAMATE PESTICIDE RESIDUES EXTRACTED FROM PURPLE YAM BY USING OPTIMUM ULTRASONIC-ASSISTED EXTRACTION

\begin{tabular}{llccc}
\multicolumn{5}{c}{ OPTIMUM ULTRASONIC-ASSISTED EXTRACTION } \\
\hline \multicolumn{1}{c}{ Sample } & \multicolumn{1}{c}{1} & \multicolumn{1}{c}{2} & 3 & 4 \\
\hline Extraction rate of pirimicrab & 99.87 & 99.87 & 100.89 & 100.79 \\
Extraction rate of carbonfuran & 100.99 & 101.75 & 101.89 & 102.65 \\
Extraction rate of aldicarb & 101.47 & 101.47 & 101.67 & 101.71 \\
Extraction rate of methomyl & 98.54 & 100.73 & 101.98 & 102.19 \\
Extraction rate of carbaryl & 100.43 & 101.43 & 102.02 & 102.54 \\
Extraction rate of efficiency & 100.26 & 101.05 & 101.71 & 101.98 \\
\hline
\end{tabular}

\section{Conclusion}

Response surface methodology was successfully employed to optimise extraction from Purple yam using ultrasonicassisted extraction. Optimised conditions for maximum extraction efficiency were determined including solvents, solvent volume, ultrasound power, ultrasound extraction time and extraction times, which were identified as controlling factors. Methomyl, pirimicarb, aldicarb, carbonfuran and carbaryl were determined by LC-MS in ultrasonic-assisted extracts from Purple yam. This study indicates that this method is suitable for sample pretreatment to analysis of carbamate pesticide residues in food, which have an application in food industry.

\section{ACKNOWLEDGEMENTS}

This work was supported by a grant from Applied Basic Research Projects of Yunnan Province (2013FZ120).

\section{REFERENCES}

1. C.C. Huang, P.Y. Chiang, Y.Y. Chen and C.R. Wang, LWT-Food Sci. Technol., 40, 1498 (2007).

2. M.R. Bhandari, T. Kasai and J. Kawabata, Food Chem., 82, 619 (2003).

3. I. Muzac-Tucker, H.N. Asemota and M.H. Ahmad, J. Sci. Food Agric., 62, 219 (1993).

4. M.M. Iwu, C.O. Okunji, G.O. Ohiaeri, P. Akah, D. Corley and M.S. Tempesta, Planta Med., 56, 264 (1990).

5. S.E. Omonigho and M.J. Ikenebomeh, Food Chem., 71, 215 (2000).

6. O.N. Ozo, J.C. Caygill and D.G. Coursey, Phytochemistry, 23, 329 (1984).

7. Y. Shoyama, Y. Nishioka, W. Herath, S. Uemoto, K. Fujieda and N. Okubo, Phytochemistry, 29, 2999 (1990).

8. K. Yoshida, T. Kondo, K. Kameda, S. Kawakishi, A.J.M. Lubag, E.M.T. Mendoza and T. Goto, Tetrahedron Lett., 32, 5575 (1991).

9. A.S. Undie and P.I. Akubue, J. Ethnopharmacol., 15, 133 (1986).

10. M. Araghiniknam, S. Chung, T. Nelson-White, C. Eskelson and R. R. Watson, Life Sci., 59, 147 (1996).

11. J.E. Kelmanson, A.K. Jager and J. Van Staden, J. Ethnopharmacol., 69, 241 (2000).

12. Y.T. Chen, W.T. Kao and K.W. Lin, Food Chem., 107, 250 (2008).

13. M. Miyazawa, H. Shimamura, S. Nakamura and H. Kameoka, J. Agric. Food Chem., 44, 1647 (1996).

14. S. Tewtrakul and A. Itharat, Bioorg. Med. Chem., 14, 8707 (2006).

15. Q.H. Wu, Q.Y. Chang, C.X. Wu, H. Rao, X. Zeng, C. Wang and Z. Wang, J. Chromatogr. A, 1217, 1773 (2010).

16. B. Mayer-Helm, L. Hofbauer and J. Muller, Rapid Commun. Mass Spectrom., 20, 529 (2006).

17. L. Sun and H.K. Lee, J. Chromatogr. A, 1014, 165 (2003).

18. R.C. Prados-Rosales, M.C. Herrera, J.L. Luque-García and M.D. Luque de Castro, J. Chromatogr. A, 953, 133 (2002).

19. X.M. Yang, O. Wang, M.Z. Wang, Y.X. Hu, W.N. Li and Z. Wang, J. Chromatogr. Sci., 46, 751 (2008).

20. I.A.W. Tan, A.L. Ahmad and B.H. Hameed, Chem. Eng. J., 137, 462 (2008).

21. X.Z. Yuan, J. Liu, G.M. Zeng, J.G. Shi, J.Y. Tong and G.H. Huang, Renew. Energy, 33, 1678 (2008).

22. M.Q. Liu, X.M. Yang, L. Zhang and G. Majetich, J. Med. Plants Res., 4, 2503 (2010).

23. Ö. Aybastier and C. Demir, J. Mol. Catal. B, 63, 170 (2010).

24. Y. Wu, S.W. Cui, J. Tang and X.H. Gu, Food Chem., 105, 1599 (2007).

25. Z.L. Pan, W.J. Qu, H.L. Ma, G.G. Atungulu and T.H. McHugh, Ultrason. Sonochem., 18, 1249 (2011).

26. J. Wang, B.G. Sun, Y.P. Cao, Y. Tian and X.H. Li, Food Chem., 106, 804 (2008). 